\title{
Biomassa Residual Vegetal ${ }^{1}$
}

Caroline Thaís Eckert ${ }^{2}$, Elisandro Pires Frigo ${ }^{3}$, Rafaela Koglin Bastos ${ }^{4}$, Alvaro Mari Junior ${ }^{5}$, Angelo Gabriel Mari $^{6}$, Ana Claudia $\mathrm{Cabral}^{7}$.

\footnotetext{
${ }^{1}$ Aceito para publicação no $3^{\circ}$ semestre de 2013

2 Tecnóloga em Biocombustível pela Universidade Federal do Paraná, Setor Palotina/PR, Brasil.

3 Engenheiro Agrícola, Mestre em Engenharia Agrícola, Engenharia de Sistemas Agroindustriais, Doutor em Agronomia, Irrigação e Drenagem, Professor Adjunto do Curso de Agronomia da UFPR, setor Palotina/PR, Brasil.

${ }^{4}$ Acadêmica em Tecnologia em Biocombustíveis pela Universidade Federal do Paraná, Setor Palotina/PR, Brasil.

${ }^{5}$ Engenheiro Ambiental, Mestrando em Energia na Agricultura pela Universidade Estadual do Oeste do Paraná, Cascavel/PR, Brasil.

${ }^{6 .}$ Engenheiro Ambiental, Mestrando em Energia na Agricultura pela Universidade Estadual do Oeste do Paraná, Cascavel/PR, Brasil.

${ }^{7}$ Engenheiro Ambiental, Mestrando em Energia na Agricultura pela Universidade Estadual do Oeste do Paraná, Cascavel/PR, Brasil.
}

Palavras-chave culturas de inverno; resíduos agrícolas; energia.

\section{Resumo}

Com o aumento da população mundial, as atividades agropecuárias tem se intensificado muito nos últimos anos. O Brasil possui uma extensa área de produção agrícola, sendo favorecido por condições propicias de cima, revelo para que muitas culturas se desenvolvam. O presente trabalho teve como intuito principal destacar algumas culturas e suas produções de biomassa, as quais podem ser transformados em fontes de energia. As culturas em destaque são: aveia preta, capim-braquiária, triticale, trigo, milho, canola e o centeio, as quais são classificadas como culturas intercalares de inverno, ou seja, podem ser produzidas intercaladas com outras culturas como a soja.

Key-words: winter crops, agricultural waste, energy.

\begin{abstract}
With the increase in world population, agricultural activities has intensified in recent years. Brazil has a large area of agricultural production, being favored by favorable conditions from above, reveal that many cultures to develop. The present work had as main aim to highlight some crops and their production of biomass, which can be transformed into energy sources. The cultures featured are: oats, signal grass, triticale, wheat, corn, canola and rye, which are classified as intercrops winter, ie, can be produced interspersed with other crops such as soybeans.
\end{abstract}

Revista Brasileira de Energias Renováveis, v. 4, p. 32-44, 2013 


\section{Introdução}

$\mathrm{Na}$ sociedade atual, onde os modos de consumo de energia se intensificam a cada dia, a busca por alternativas eficazes de produção, distribuição e diversificação de energia tornam-se essenciais diante da dependência dos recursos energéticos.

Conforme Braga (2005), as fontes renováveis geralmente são provenientes (direta ou indiretamente) da energia solar. As energias renováveis representaram em 2010 5,9\% da matriz energética brasileira, sendo observado um aumento ao passar dos anos devido diversos fatores como disponibilidade de informação, conhecimento e tecnologias de baixo custo operacional com alto índice de eficiência energética.

Biomassa é toda a massa de matéria viva, animal ou vegetal, que vive em equilíbrio numa determinada área da superfície terrestre. Do ponto de vista da produção de energia é toda a massa orgânica que pode ser usada como combustível ou para a sua produção. Apesar dos combustíveis fósseis como petróleo, carvão ou gás natural, também sejam derivados de matéria orgânica, precisam de milhares de anos para serem gerados, por isso não são considerados biomassa pois não são recursos naturais renováveis a curto prazo (NOGUEIRA e RENDEIRO, 2008).

Dentre a Biomassa vegetal destacam-se os resíduos agrícolas, qual segundo WERTHER et al. (2000), apresentam um potencial de alta energia. O Brasil apresenta um elevado potencial de matérias primas (resíduos) para produção da bioenergia, devido suas grandes áreas cultiváveis, condições climáticas e solos favoráveis. A energia presente na biomassa é transformada em combustíveis sólidos, líquidos e gasosos através de processos de conversão físicos, químicos e biológicos (MARTINI, 2009).

Em 2010, a participação da biomassa na matriz energética brasileira foi de $31 \%$, dos quais, $17,7 \%$ de produtos da cana, 9,5\% de lenha e 3,8\% de outros resíduos. Para 2020, os estudos do Ministério de Minas e Energia mostram que a biomassa deve passar de 35\% de participação na matriz (MARTINI, 2009). O objetivo geral do trabalho foi apresentar diferentes culturas intercalares de inverso que apresentam grande potencial de produção de biomassa.

\section{Material e métodos}

O presente trabalho é uma revisão literária, onde todos os dados sobre as culturas energéticas, fontes de biomassa vegetal, foram retirados da literatura já existente. 


\section{Biomassa}

A Biomassa é definida como todo material orgânico de origem vegetal. Este material deriva da reação entre gás carbônico $\left(\mathrm{CO}_{2}\right.$ no ar), água $\left(\mathrm{H}_{2} \mathrm{O}\right)$ e luz solar, ou seja, pelo processo de fotossíntese, qual armazena fração de energia solar nas ligações químicas de seus componentes (SOUZA; SORDI e OLIVA, 2002).

Basicamente a Biomassa é um hidrocarboneto, qual possui átomos de oxigênio na sua composição química, diferentemente dos combustíveis fósseis. A presença desse átomo faz com que a biomassa requeira menos oxigênio do ar, sendo menos poluente, mas consequentemente sua quantidade de energia a ser liberada é reduzida, diminuindo assim o seu Poder Calorífico Superior (NOGUEIRA; RENDEIRO, 2008).

A Biomassa Vegetal é considerada também como resíduo ligno-celulósico, qual varia tanto no seu teor de celulose (40-50\%), hemicelulose (20-40\%) quanto lignina (MARTINI, 2009).

Quando os laços adjacentes entre moléculas de carbono, hidrogênio e oxigênio são quebrados por combustão, digestão, ou decomposição, estas substâncias liberam sua energia química armazenada. A utilização da biomassa como matéria prima de conversão depende das propriedades químicas e físicas das moléculas (MCKENDRY, 2002).

\section{Biomassa agrícola}

Segundo Nonhebel (2007), a biomassa mais significativa em relação à energia são as obtidas de culturas energéticas e resíduos agrícolas, estes se originam de material vegetal gerados no sistema de produção de outros produtos.

São considerados resíduos de origem agrícola aqueles que apresentam grande potencial para serem utilizados na produção de energia, como exemplo, resíduos de culturas agrícolas e de seu beneficiamento ou as palhas, cascas de frutos, cereais, os bagaços, os resíduos das podas de pomares e vinhas, rejeitos madeireiros, entre outros (SAITER, 2008).

Segundo Matos (2005), a produção de resíduos agrícolas é variável, pois depende da espécie cultivada, o destino da mesma, das condições climáticas e da fertilidade do solo, entre outros. O conteúdo de nutrientes dos resíduos de culturas também pode variar, pois as mesmas, como a produção, dependem da fertilidade do solo e tipo de material.

Os países com o cultivo agrícola ativo e em grandes dimensões cultiváveis são os maiores fornecedores de matérias primas para a produção de bioenergia. Estes, segundo o relato do estudo sobre o tema inserido no Plano Nacional de Energia 2030, a melhor região do planeta para a produção da biomassa é a faixa tropical e subtropical, entre o Trópico de 
Câncer e o Trópico de Capricórnio. A faixa tropical e subtropical do planeta abrange alguns países das Américas Central e do Sul, como o Brasil. Além da grande quantidade de terra agriculturável, nosso país apresenta solo e condições climáticas adequadas (BCSD PORTUGAL, 2007).

\section{Tecnologias de Conversão de Biomassa em Energia}

A ANEEL (2008) define biomassa como qualquer matéria orgânica que possa ser transformada em energia mecânica, térmica ou elétrica. Dependendo da origem, pode ser classificada em: florestal (madeira, principalmente), agrícola (soja, arroz e cana-de-açúcar, entre outras) e rejeitos urbanos e industriais (sólidos ou líquidos, como o lixo). Os derivados obtidos dependem tanto da matéria-prima utilizada (cujo potencial energético varia de tipo para tipo) quanto da tecnologia de processamento para obtenção dos energéticos.

No Brasil o uso mais importante da biomassa está relacionado com o desenvolvimento da frota de veículos a álcool (de cana-de-açúcar), que veio a criar uma alternativa mais promissora e ambientalmente mais adequada que os derivados de petróleo. Razões associadas a lobbies econômicos e a não-consideração adequada dos custos ambientais colocaram, no entanto, essa tecnologia se encontra em compasso de espera.

Conforme Brás et al. (2007) para transformar a biomassa em energia existem diversas tecnologias, sendo os processos termoquímicos e biológicos os mais utilizados. Este último baseia-se na utilização de microrganismos para transformar as moléculas presentes na biomassa em compostos mais simples, porém com alto valor energético, dentre este processo estão a Fermentação e Digestão Anaeróbia. Outrem os processos termoquímicos utiliza o calor para transformar a biomassa em energia, esta tecnologia vem sendo desenvolvida para converter a biomassa residual de atividades agrícola, florestais e industriais. Nesta tecnologia encontram-se três tipos de processos quais dependem da quantidade de oxigênio presente (pirólise, gaseificação e combustão).

\section{Recursos Renováveis}

Hoje há uma forte consciência de que a energia, na sua produção e no seu uso, tem um impacte ambiental que urge minimizar. Relativamente às fontes de energia fósseis, assiste-se hoje à redescoberta do gás natural e à gestão mais rigorosa do petróleo e do carvão. O uso de energias renováveis é visto, agora, como uma prioridade, sendo hoje dedicados largos fundos e meios de investigação ao desenvolvimento da sua utilização. A nível europeu, as energias renováveis são, ainda, uma componente de pequena dimensão no total da energia 
consumida, mas existe o objetivo de, até 2020, constituírem no mínimo $18 \%$ das origens de energia necessárias (BRAGA, 1999).

O potencial existente para a produção e utilização de biogás de recursos renováveis no Paraná é constituído sobretudo pelos resíduos da colheita e do processamento, bem como pelos subprodutos da produção de biodiesel e de bioetanol. No caso da produção de bioetanol, o subproduto é a vinhaça e na produção de biodiesel, é a glicerina e eventualmente o bolo resultante da prensa de plantas oleaginosas. No entanto, devido ao seu valor econômico, este último vai quase sempre para a produção de ração (RE-PIC, 2007). Para o estado do Paraná, existe uma estimativa aproximada do potencial para o aproveitamento dos subprodutos da produção de biocombustível, que segundo a ANEEL é de pelo menos $1.000 \mathrm{GWh} / \mathrm{ano}$ (ANNEL, 2002).

A concepção de Ambiente foi evoluindo, existindo actualmente a percepção de que os problemas ambientais não se reduzem apenas à degradação do ambiente físico e biológico, mas que englobam dimensões sociais, económicas e culturais, como a pobreza e a exclusão, sendo a degradação ambiental percebida como um problema planetário que decorre do tipo de desenvolvimento praticado pelos países. A qualidade do ambiente passa não só por uma mudança das políticas nacionais e internacionais, que devem privilegiar o crescimento sustentável, mas também por novos conhecimentos, valores e atitudes por parte dos cidadãos, os quais devem ter uma participação activa na sociedade democrática em que vivem, contribuindo para a defesa do ambiente.

Nos últimos dez anos as questões ambientais instalaram-se no palco das preocupações públicas, sociais e políticas nacionais. Surge assim a imperiosa necessidade de encarar o homem, o seu ambiente e as suas intervenções sobre ele numa perspectiva integrada e de equilíbrio (SCHMIDT, 1999). Apontando, assim, directamente no sentido de uma educação para a cidadania. educar para a cidadania é educar para o conhecimento, valores da democracia como a solidariedade, a cooperação, a tolerância, o respeito pela diversidade e por pontos de vista diferentes, a paticipação, a autonomia, o pensamento crítico e a responsabilidade (NOVO, 2005). Trata-se de estabelecer uma organização entre sociedade e Ambiente que seja realmente sustentável e que passe por conceitos e práticas ajustadas à realidade, obtidos através de um processo de formação de cidadãos interessados, atentos e realmente preocupados com a resolução de problemas da sociedade onde estão inseridos (MORGADO et al. 2000).

\section{Culturas intercalares de inverno}




\section{Aveia preta (avena strigosa)}

A aveia-preta é uma das principais plantas utilizadas pelos produtores com a finalidade de formação de cobertura do solo. Dentre as principais vantagens do cultivo da aveia-preta destacam-se: ciclagem de nutrientes, mobilização de cátions no perfil do solo bem como modificações químicas no perfil do solo que aumentam a disponibilidade de nutrientes. Essas vantagens proporcionam benefícios ao solo e às culturas comerciais cultivadas em sucessões. (SPAGNOLLO, 2000; AMADO e MIELNICZUK, 2000)

A aveia preta tem uma boa capacidade de afilhamento, necessidades reduzidas de nutrientes e uma alta tolerância a épocas de seca. A sua rápida cobertura do solo melhora as propriedades químicas e físicas do solo. No Brasil, a aveia preta é muito popular entre as empresas produtoras de gado leiteiro. Neste caso, as manadas são conduzidas diretamente para os campos para pastarem. Geralmente, encontra-se a aveia preta como cultura precedente da soja. Às vezes, porém, também é efetuado um cultivo antes de semear o milho, o que requer uma elevada adubação N. A densidade de semeadura para a produção de biomassa deverá aumentar em comparação com a produção de sementes e encontra-se em 40 a 60 kg/ha. As produções de biomassa oscilam entre 15 e 40 t FM/ha ou entre 2 e 111 TM/ha (CALEGARI, 1990).

\section{Capim-braquiária (brachiaria spp ruziziensis)}

A planta forrageira tem uma boa tolerância à seca e necessita de uma precipitação anual de mais de $1.000 \mathrm{~mm}$. Devido à reduzida tolerância ao frio, a planta só cresce em zonas com temperaturas acima do ponto de congelamento. As produções de matéria seca no Brasil encontram-se entre 6 t/ha (extensivo) e 12 t/ha com dosagens de nitrogênio de $150 \mathrm{~kg} / \mathrm{ha}$. Porém, segundo Ivo Mello, as produções nas primeiras tentativas do sistema de culturas associadas são de apenas 4 a 6 t TM/ha (MELLO, 2010). Muito utilizada na alimentação animal.

\section{Triticale (Triticosecale Wittmack)}

O triticale é um cruzamento entre o trigo (triticum aestivum L.) como parceiro feminino e centeio (Secale cereale L) como parceiro masculino. As variedades cruzadas são altamente estéreis. Por isso, os conjuntos de cromossomos têm de ser duplicados artificialmente através do tratamento dos germes com colchicina, o alcalóide dos narcisos-dooutono, para obter plantas férteis. O nome é composto por TRITIcum e seCALE. As aristas deste tipo de cereal têm cerca de 3-5 cm de comprimento e são quadrangulares. $\mathrm{O}$ triticale foi 
cultivado associar a pouca necessidade de cuidados do centeio à qualidade do trigo. Com uma área cultivada de 5.500 ha, esta cultura até o momento desempenha apenas um papel secundário na região da Bacia do Paraná 3. As produções médias de sementes de 2005 a 2009 encontravam-se entre 18 e $24 \mathrm{dt} / \mathrm{ha}$ (FAO, 2009), enquanto que as produções de biomassa foram de 5 a 8 t TM/ (CALEGARI, 1990).

É uma fonte alternativa para os produtores rurais, utilizada como fonte de proteína na formulação da ração animal, vindo a reduzir custos de produção.

\section{Trigo (triticum durum)}

Devido às exigências em relação ao clima, o cultivo de trigo no Brasil apenas é possível em pequenas dimensões. Os fatores limitadores são, por um lado, as temperaturas elevadas e, por outro, a distribuição desigual da precipitação. Por isso, o trigo no Brasil só é cultivado no Sul, nas zonas de clima temperado e como segunda colheita. Ao contrário da Europa, onde é cultivado principalmente trigo comum (triticum aestivum), no Sul do Brasil encontra-se predominantemente trigo duro (triticum durum). As produções de sementes de 15 a 25 t/ha são significativamente inferiores às previsões de produção europeias e devem-se ao efeito reduzido da verbalização (FAO, 2009).

É uma das culturas mais importantes de inverso ao lado do milho, com produções de matéria de 4 a 7 t/ha.

\section{Milho (Zea mays)}

Segundo o Ministério da Agricultura, o Brasil é o terceiro maior produtor mundial de milho, totalizando 53,2 milhões de toneladas na safra 2009/2010. A primeira idéia é o cultivo do grão para atender ao consumo na mesa dos brasileiros, mas essa é a parte menor da produção. O principal destino da safra são as indústrias de rações para animais.

Cultivado em diferentes sistemas produtivos, o milho é plantado principalmente nas regiões Centro-Oeste, Sudeste e Sul. O grão é transformado em óleo, farinha, amido, margarina, xarope de glicose e flocos para cereais matinais.

A cultura do milho ocupou, em 2006, uma área em torno de 12,9 milhões de hectares, responsável por uma produção de cerca de 41,3 milhões de toneladas de grãos, apresentando um rendimento médio de $3.198 \mathrm{~kg}$ ha -1 (3.298 kg ha -1 na safra e $2.907 \mathrm{~kg}$ ha -1 na safrinha), de acordo com a Conab. Mesmo considerando o rendimento dos estados da região Centro-Sul, que foi de $3.893 \mathrm{~kg}$ ha -1 esse rendimento é muito inferior ao que poderia ser obtido, levandose em consideração o potencial produtivo da cultura, que é demonstrado que a cultura do 
milho aumenta sua rentabilidade e sua vantagem comparativa com outras culturas quando sua produtividade é aumentada. (EMBRAPA, 2008).

\section{Canola (Brassica napus L.)}

As pesquisas e o cultivo de Brassica napus L. no Brasil foram iniciadas pela COTRIJUÍ, em 1974, em Ijuí, no noroeste do Rio Grande do Sul com a cultura da colza. O cultivo alcançou o Paraná-PR já no início dos anos 80. No entanto, na década de 90, observou-se uma retração do cultivo da oleaginosa. Segundo Tomm (2005), a partir do ano de 2001, houve uma retomada na expansão da área de cultivo comercial de canola, sobretudo nos estados do Rio Grande do Sul e do Paraná, chegando ao sudoeste de Goiás em 2003. Embora ainda pouco semeada no Brasil, apenas 35.131 hectares em 2009, mundialmente, é a terceira planta oleaginosa mais produzida e seu maior consumo ocorre em países mais desenvolvidos. A canola no Brasil constitui uma excelente opção de cultivo com a destinação à alimentação humana bem como para fins agroenergéticos, especialmente, para a exportação à Europa e outros países com invernos rigorosos.

Outra vantagem interessante que se apresenta ao agricultor brasileiro é a possibilidade de rotação de cultivos, com semeadura da canola no outono-inverno (semeadura entre 15 de abril a 30 de junho no Rio Grande do Sul) ou na safrinha (semeadura em fevereiro a março) na região Centro-Oeste. Com estas características positivas, o cultivo da canola tende a aumentar no Brasil, tanto pela elevada disputa pelo produto no mercado brasileiro e europeu como por ser uma ótima opção econômica para o agricultor brasileiro. Se seguir o exemplo de pesquisa e desenvolvimento e a capacidade empreendedora observada com o cultivo de soja no Brasil, o país poderá se transformar em importante produtor e exportador de canola (TOMM, 2006).

\section{Centeio (Secale cereale L.)}

O cultivo de centeio (Secale cereale L.) se destina à alimentação humana (fabricação de farinha, cerveja, alguns tipos de whisky e grande parte de vodkas), à alimentação animal (fabricação de ração, silagem ou pastoreio) e à adubação verde No Brasil, o centeio foi introduzido por imigrantes alemães e poloneses no século XIX e seu cultivo tem se concentrado na região sul do país, com registros de cultivo no Mato Grosso do Sul a partir da década de 90. No período de 1999- 2003, o estado do Rio Grande do Sul foi responsável, na média, por 77,0\% da produção de centeio brasileira. Os estados do Paraná, Mato Grosso do 
Sul e Santa Catarina tiveram participação média na quantidade produzida de $19,1 \%, 2,1 \%$ e $1,8 \%$, respectivamente, no referido período (EMBRAPA, 2007).

\section{Cevada (Hordeum vulgare sp. Vulgare)}

Segundo MACGREGOR e FINCHER (1993), no Brasil, o uso de cevada tem sido exclusivamente para consumo na indústria cervejeira e ração animal. Por este motivo, o cultivo sempre esteve limitado à região temperada nos planaltos do Rio Grande do Sul, em Santa Catarina e no Paraná, onde o clima favorece a produção de cevada com qualidade para a fabricação de cerveja.

Dentre as variedades de cevada, merecem destaque os cultivares nus (ALEXANDER, 1995). Estes cultivares tem sido redescobertos recentemente por suas inúmeras aplicações na forma de grão integral e/ou por seu valor como ingrediente. Seu uso tem sido investigado por apresentar maiores quantidades de amido, proteína, e b-glucanas, o maior representante de fibra alimentar solúvel. $\mathrm{O}$ amido destaca-se por ser o maior componente nos grãos de cevada (50-75\%), sendo sua quantidade dependente de cada variedade e meio ambiente. É constituído basicamente por moléculas lineares e ramificadas de amilose (aproximadamente 30\%) e amilopectina (aproximadamente 70\%) respectivamente (ZHANG, et al.2001 e YOU et al. 2001).

Possui inúmeras aplicações na indústria alimentícia (ingrediente, bebidas, aditivo, substrato para fermentação, transformação enzimática) e não-alimentícia (papel, tecidos, adesivos), e ainda pode ser caracterizado como potencial componente em embalagens biodegradáveis. Adicionalmente, o amido possui aplicações no setor farmacêutico e, mais recentemente, na cosmetologia (TESTER, R. F.; KARKALAS, 2001).

As propriedades físico-químicas dependem da origem genética deste amido, condições climáticas de produção, parâmetros tecnológicos (temperatura, conteúdo de água, etc.), do manejo da matéria-prima, das modificações físicas (tratamentos térmicos) ou químicas realizadas. Em função da grande variedade, usos e propriedades, o campo de caracterização de amido é imenso (RULES, 2000).

\section{Área cultivada disponível e Rendimento}

De acordo com o IBGE (2013), a primeira estimativa da safra nacional de cereais, leguminosas e oleaginosas (caroço de algodão, amendoim, arroz, feijão, mamona, milho, soja, aveia, centeio, cevada, girassol, sorgo, trigo e triticale) para 2013 totaliza produção da ordem 
de 183,3 milhões de toneladas, 13,1 \% superior à obtida em 2012 (162,1 milhões de toneladas).

\section{Conclusões}

As culturas abordas se destacam pela produção de biomassa, a qual pode ser convertida em diferentes formas de energia; e ainda por serem culturas de inverno, que podem ser produzidas intercaladas com a soja que não se adapta em períodos de inverno, garantindo ao produtor fonte de renda adicional, como uma segunda safra.

\section{Referências}

ABBASI, T. Biomass energy and the environmental impacts associated with its production and utilization. Renewable and Sustainable Energy Reviews. India: Elsevier, v. 14, p. 919937, 2010.

ALEXANDER, R. J. Fat Replacers Based on Starch. Cereal Foods World, v.40, n.5, 1995.

AMADO, T. J. C.; MIELNICZUK, J. Estimativa da adubação nitrogenada para o milho em sistemas de manejo e culturas de cobertura do solo. Revista Brasileira de Ciência do Solo, Viçosa, v. 24, n. 3, p. 553-560, 2000.

ANNEL: Atlas de Energia. Disponível em: < http://www.aneel.gov.br/aplicacoes/atlas/pdf/05Biomassa(2).pdf $\geq$. Acesso em: 07/08/2012.

BAKER, L. A.; RAYAS-DUARTE, P. Retrogradation of Amaranth Starch at Different BRAGA, B.; HESPANHOL, I.; CONEJO, J.G.L.; et al. Introdução à Engenharia Ambiental. 2 ed. São Paulo: Pearson, 2005. 336 p.

Braga, J. Guia do Ambeinte: As empresas portuguesas e o desafio ambiental. Lisboa: Monitor. 1999.

BRÁS, A. M; MIRANDA, F. HIPÓLITO, L; DIAS, L. S. Biomassa e Produção de Energia. 2008. Dísponivel em: http://portal.ipvc.pt/images/ipvc/esa/pdf/biomassa.pdf. Acesso em: 07/08/2012

CALEGARI, A. Plantas para adubação verde de inverno no sudoeste do Paraná. Londrina: Instituto Agronômico do Paraná, 1990. 37 p. (Boletim Técnico, 35).

EMBRAPA - Empresa Brasileira de Pesquisa Agropecuária. Milho e Sorgo. Disponível em: <http://www.agricultura.gov.br/vegetal/culturas/milho $\geq$. Acesso em: 05/08/2012.

EMBRAPA. Trigo. In: BOLETIN DE PESQUISA E DESENVOLVIMENTO ONLINE. Passo Fundo - RS, 2007. 
FAO. Daten entnommen aus faostaT. 2009. Disponível em: <http://faostat.fao.org/site/567/DesktopDefault.aspx> Acesso em: 09/08/2012 IBGE - Instituto Brasileiro de Geografia e Estatística. 2013. Disponível em: $<$ http://saladeimprensa.ibge.gov.br/noticias? view=noticia\&id=1\&idnoticia=2319\&busca=\&t= en-enero-el-ibge-estima-cosecha-granos-el-13-1-superior-la>. Acesso em: 04/07/2013.

MACGREGOR, A. W.; FINCHER, G. B. Carbohydrates of the barley grain. In: BARLEY - CHEMISTRY AND TECHNOLOGY. ST. PAUL, MINNESOTA - USA: AACC, 1993. P. $73-128$

MARTINI, P. R. R. Conversão Pirolítica de Bagaço Residual da Indústria de Suco de Laranja e Caracterização Química dos Produtos. 2009. Dissertação (mestrado em química) PPGQ, UFSM, Santa Maria: 2009.

MATOS, A. T. Tratamento de resíduos agroindustriais. Curso sobre tratamento de Resíduos Agroindustriais, Fundação Estadual do Meio Ambiente. Viçosa:2005.

MORGADO, F; PINTO, R.; LEITÃO, F. Educação Ambiental - para um ensino interdisciplinar e experimental da Educação Ambiental. Lisboa: Plátano Edições. 2000.

NOGUEIRA, M. F. M.; RENDEIRO, G. Caracterização Energética da Biomassa Vegetal.

BARRETO, E. J. F. (Coord). Combustão e Gaseificação da Biomassa Sólida: Soluções Energéticas para a Amazônia. Brasilia: Ministério de Minas e Energia, 2008. p. 52-63.

NONHEBEL, S. Energy from agricultural residues and consequences for land requirements for food production. Agricultural Systems. Holanda: Elsevier, v. 94, p. 586$592,2007$.

RUALES, J.; CARPIO, C.; SANTACRUZ, S.; SANTACRUZ, P.; BRAVO, J. Manual de Métodos de Caracterización de Carbohidratos. ed. Equador: Escuéla Politécnica Nacional, Departamento de Ciencia de Alimentos y Biotecnología, 2000. 113 p.

SAITER, O. Utilização de resíduos agrícolas e florestais como fonte de energia para a secagem de grãos de Coffea canephora var. Conilon. 2008

SCHMIDT, L. Portugal Ambiental - Casos e Causas. Oeiras: Celta Editora. 2008.

SOUZA, S. N. M; SORDI, A.; OLIVA, C. A. Potencial de energia Primária de Resíduos Vegetais no Paraná. $4^{\circ}$ Encontro de Energia no Meio Rural. 2002.

SPAGNOLLO, E. Plantas de cobertura intercalares ao milho em sistemas de cultivo mínimo e convencional. 121f. Dissertação (Mestrado em Ciência do Solo) -Programa de Pósgraduação em Ciência do Solo, Universidade do Estado de Santa Catarina. 2000. 
TESTER, R. F.; KARKALAS, J. The effects of Environmental Conditions on the Structural Features and Physico-chemical Properties of Starches. Starch/Starke, v.53, p.513-519, 2006.

TOMM, G. O. Canola: alternativa de renda e benefícios para os cultivos seguintes. Revista Plantio Direto, v. 15, n. 94, p. 4-8, jul./ago. 2006. Disponível em: $<$ http://www.cnpt.embrapa.br/culturas/canola/canola-rev_plantio_direto2006.pdf $>$. Acesso em: 04/07/2013.

TOMM, G. O. Situação em 2005 e perspectivas da cultura de canola no Brasil e em países vizinhos. Passo Fundo: Embrapa Trigo, 2005. 21 p. html. (Embrapa Trigo. Boletim de pesquisa e desenvolvimento online, 26). Disponível em: <http://www.cnpt.embrapa.br/biblio/bp/p_bp26.htm>. Acesso em: 04/07/2013.

Volume 83, Número 1, maio 2002, p. 37-46, 2007.

WERTHER J. et al. Combustion of agricultural residues. Progress in energy and combustion science. Alemanha: Pergamon, v.26, p. 1-27, 2000.

YOU, S.; IZYDORCZYK, M. S. Molecular characteristics of barley starches with variable amylose content. Carbohydrate Polymers, v.49, n.1, p.33-42, 2002 